\title{
Chromosome instability and nibrin protein variants in NBS heterozygotes
}

\author{
Caterina Tanzarella ${ }^{1}$, Antonio Antoccia ${ }^{1}$, Emanuela Spadoni ${ }^{2}$, Alessandra di Masi ${ }^{1}$, \\ Vanna Pecile ${ }^{3}$, Eliana Demori ${ }^{3}$, Raymonda Varon $^{4}$, Gian Luigi Marseglia ${ }^{5}$, Luciano Tiepolo ${ }^{2}$ \\ and Paola Maraschio*,2 \\ ${ }^{1}$ Università degli Studi di Roma, Roma Tre, Italy; ${ }^{2}$ Biologia Generale e Genetica Medica, Università degli Studi di Pavia, \\ Italy; ${ }^{3}$ IRCCS, Burlo, Garofolo, Trieste, Italy; ${ }^{4}$ Institute of Human Genetics, Charité, Humboldt-University, Berlin, \\ Germany; ${ }^{5}$ Clinica Pediatrica, IRCCS San Matteo, Pavia, Italy
}

The frequency of spontaneous chromosome abnormalities in peripheral blood lymphocytes and the X-ray G2 sensitivity in lymphoblastoid cell lines (LCL) have been evaluated in heterozygous subjects from three unrelated Nijmegen Breakage Syndrome (NBS) families, characterised by different mutations in the NBS1 gene. In all the 13 NBS heterozygotes analysed, we found spontaneous chromosome instability consisting in chromosome and chromatid breakages and rearrangements, while radiosensitivity was similar to that of control LCLs in seven out of eight tested NBS heterozygotes. The densitometric analysis of nibrin by immunoblotting indicated only a slight reduction in some of the LCLs from NBS carriers, whereas the immunoprecipitation assay appears a more reliable tool to detect NBS carriers. By means of immunoprecipitation, we investigated two homozygous and four heterozygous subjects. In the cells of the NBS patient 668 , with the mutation $900 \mathrm{del} 25$, an alternative form of nibrin with a molecular weight of approximately $55 \mathrm{kDa}$ has been detected. This variant protein, together with the normal p95, was also found in the LCL 34 established from a carrier of the same family. Signals of nibrin with a molecular weight lower than $95 \mathrm{kDa}$, but higher than that observed in LCLs 668 and 34, were detected also in three carriers from the family with mutation 835 del 4 .

European Journal of Human Genetics (2003) 11, 297-303. doi:10.1038/sj.ejhg.5200962

Keywords: Nijmegen breakage syndrome; heterozygotes; spontaneous chromosome instability; radiosensitivity; nibrin; variant NBS1 proteins

\section{Introduction}

Patients affected by Nijmegen breakage syndrome (NBS) have biallelic mutations in the NBS1 gene, mapped on chromosome $8 \mathrm{q}_{2} 1^{1-3}$ and subsequently cloned. ${ }^{4,5}$ It encodes a $95-\mathrm{kDa}$ protein called nibrin, a member of the hMre11/hRAD50 protein complex, involved in cellular response to DNA double-strand breaks (DSBs). ${ }^{6}$ In NBS cell lines, Maser $e \mathrm{al}^{7}$ demonstrated that an alternative mode

*Correspondence: Dr P Maraschio, Biologia Generale e Genetica Medica, Università degli Studi di Pavia, via Forlanini 14, 27100 Pavia, Italy. Tel: +39 0382 507726; Fax: +39 0382 525030; E-mail: marasc@unipv.it Received 13 May 2002; revised 9 December 2002; accepted 2 January 2003 of translation originates variant NBS1 proteins of lower molecular weight. The affected patients present with microcephaly, a distinct facial appearance, growth retardation, immunodeficiency, cytogenetic abnormalities, radiosensitivity and high susceptibility to lymphoid malignancy. ${ }^{8}$ In $40 \%$ of the patients, in fact, a malignancy occurs before the age of $21 .{ }^{9}$ About $90 \%$ of the NBS patients are of Slav origin and carry the major founder mutation 657del5 in exon 6; eight distinct mutations have been found in families of different ethnic origin. ${ }^{10-12}$

In NBS cells, chromatid and chromosome breakages, acentric fragments, asymmetrical multiradial configurations among nonhomologous chromosomes and sporadic or clonal translocations and inversions are present. 
Ionising radiation and radiomimetic chemicals can further increase chromosome instability. Data about spontaneous and induced chromosome fragility in NBS heterozygotes are scanty, but indicate an instability higher than that found in the normal population. ${ }^{13-15}$ An epidemiological survey carried out on 142 blood relatives indicated that NBS heterozygous subjects show a significantly increased incidence of malignant tumours. ${ }^{16}$ After the cloning of the NBS1 gene, attempts have been made to evaluate its possible involvement in the pathogenesis of breast cancer, ${ }^{17}$ childhood acute lymphoblastic leukaemia, ${ }^{18}$ primary central nervous system lymphoma ${ }^{19}$ and B- and T-cell lymphomas. ${ }^{20-22}$ In this context, the cytogenetic identification of heterozygotes in the general population may be useful in genetic counselling and to minimise their exposure to chemical and physical DNA-damage-inducing agents.

In the present paper, we have evaluated the frequency of spontaneous chromosome abnormalities in peripheral blood lymphocytes and the sensitivity towards X-rays in lymphoblastoid cell lines (LCL) treated in the G2-phase of the cell cycle in heterozygous relatives from three unrelated NBS families, characterised by different mutations in the NBS1 gene. Furthermore, the levels of NBS1 protein were assessed in two families by means of immunoblotting and the presence of alternative forms of nibrin was investigated by immunoprecipitation in two homozygous and four heterozygous subjects.

\section{Patients and methods Patients}

Chromosome instability was evaluated in 13 NBS carriers belonging to three noncorrelated families with different mutations (Table 1). In the first family, the proband $(1548)^{23}$ was homozygous for the mutation 835del4 in exon 7; his nonconsanguineous parents are heterozygous for the same mutation, present also in the propositus' sister, in the maternal aunt and grandmother and in two cousins. In the second family, the proband $(668)^{24}$ is homozygous for the mutation 900del25 in exon 8; her nonconsanguineous parents and her two brothers are carriers of the same mutation. In the third family, the proband is a girl (BS) who came to our observation after she developed a lymphoma. ${ }^{25}$ She is the only child of nonconsanguineous parents from the northern-eastern part of Italy. The propositus is homozygous and the parents heterozygous for the classic mutation $657 \mathrm{del} 5$. At the time of blood sampling, no one of the analysed heterozygotes had developed a cancer. Two groups of healthy age-matched

Table 1 Spontaneous chromosome instability in the three NBS families

\begin{tabular}{|c|c|c|c|c|c|c|c|}
\hline & & & & Aberrations & & & \\
\hline Subject/code & Age & $N C A$ & $A b . M(\%)$ & $c h t b$ & chrb & $p v z / m b$ & $\mathrm{cr}$ \\
\hline \multicolumn{8}{|c|}{ Family 1 with mutation 835 del 4} \\
\hline Propositus/1548 & 6 & 49 & $30(61.2)$ & See Tupler et al. ${ }^{23}$ & & & \\
\hline Mother/1431 & 49 & 99 & $8(8.1)$ & 2 & 1 & 2 & $1 \mathrm{t}, 1 \mathrm{dic}, 2$ del, 2 frag ace \\
\hline Father/1451 & 49 & 98 & $11(11.2)$ & 3 & 6 & 0 & 1t, 1del, 4der, $1 \mathrm{mar}$ \\
\hline Sister/1452 & 24 & 97 & $8(8.2)$ & 2 & 0 & 0 & $1 \mathrm{t}, 1 \mathrm{dic}, 2 \mathrm{del}, 1$ per inv, $1 \mathrm{r}$ \\
\hline Grandmother/708 & 77 & 97 & $21(21.6)$ & 4 & 4 & 0 & $8 \mathrm{t}, 1 \mathrm{trc}, 3$ del, 1 per inv, 5 mar, 3 frag ace \\
\hline Maternal aunt/995 & 51 & 72 & $9(12.5)$ & 4 & 1 & 0 & $1 \mathrm{t}($ complex $), 1$ del, 2 per inv \\
\hline Cousin/991 & 27 & 96 & $6(6.3)$ & 3 & 1 & 0 & $1 \mathrm{t}, 2$ del \\
\hline Cousin/494 & 17 & 94 & $5(5.3)$ & 1 & 2 & 0 & 1del, 1 per inv \\
\hline \multicolumn{8}{|c|}{ Family 2 with mutation 900del25 } \\
\hline Proposita/668 & 2 & 152 & $77(50.7)$ & See Maraschio et al. ${ }^{13}$ & & & \\
\hline Mother/579 & 36 & 50 & $15(30.0)$ & 15 & 4 & 0 & 1 per inv, 1 qr \\
\hline Father/473 & 38 & 49 & $12(24.5)$ & 13 & 2 & 0 & 4del, $1 \mathrm{mar}$ \\
\hline Brother/35 & 12 & 101 & $8(7.9)$ & 6 & 0 & 0 & $1 \mathrm{t}, 1 \mathrm{del}$ \\
\hline Brother/34 & 6 & 100 & $12(12.0)$ & 12 & 0 & 0 & 0 \\
\hline \multicolumn{8}{|c|}{ Family 3 with mutation 657 del5 } \\
\hline Proposita/BS & 11 & 46 & $22(47.8)$ & 3 & 3 & 0 & $10 t$, 3del, 3per inv \\
\hline Mother/BM & 43 & 100 & $14(14.0)$ & 5 & 5 & 0 & $3 t, 1 r$ \\
\hline Father/BF & 44 & 100 & $5(5.0)$ & 2 & 2 & 0 & 1 per inv \\
\hline Controls $(n=12)$ & $5-49$ & 799 & $43(5.4)$ & 13 & 6 & 1 & $12 \mathrm{t}, 1 \mathrm{dic}, 8 \mathrm{del}, 1 \mathrm{ins}, 2$ per inv, $1 \mathrm{mar}$ \\
\hline
\end{tabular}

NCA, number of cells analysed; Ab.M, abnormal metaphases; chtb, chromatid breaks; chrb, chromosome breaks; pvz/mb, pulverisations/cells with multiple breaks; $\mathrm{cr}$, chromosome rearrangements 
controls included 12 individuals aged between 5 and 49 years and seven subjects aged between 60 and 90 years, respectively.

\section{Cytogenetic analysis}

Chromosome analysis of the NBS carriers and of healthy age-matched controls was carried out on 72-h PHAstimulated lymphocytes, according to standard procedures. Slides were conventionally stained with Giemsa to evaluate chromatid (chtb) and chromosome breaks (chrb) and subsequently $\mathrm{Q}$ banded to identify rearranged chromosomes.

LCLs were obtained by incubating peripheral blood cells with supernatant containing Epstein-Barr virus (EBV) in the presence of $600 \mathrm{ng} / \mathrm{ml}$ cyclosporin A in RPMI (Gibco) with $20 \%$ of foetal calf serum and grown in the same medium complemented with 15\% heat-inactivated serum (HyClone), L-glutamine and antibiotics at $37^{\circ} \mathrm{C}$ in a $5 \%$ $\mathrm{CO}_{2}$ atmosphere.

\section{Induced chromosome aberrations}

Radiosensitivity was evaluated in eight NBS heterozygotes. Exponentially growing cells were exposed to 15-30 cGy Xrays (Gilardoni apparatus, $70 \mathrm{cGy} / \mathrm{min}, 250 \mathrm{kV}, 6 \mathrm{~mA}$, $0.2 \mathrm{~mm} \mathrm{Cu}$ filter), and harvested $3 \mathrm{~h}$ later, after addition of $5 \times 10^{-6} \mathrm{M}$ colchicine. Routine air-dried preparations and Giemsa staining were carried out; chtb aberrations were scored in 100 metaphases in three experiments. Gaps were not included in the total rate.

\section{Western blot analysis for nibrin}

Protein extraction was carried out as previously described. ${ }^{26}$ Briefly, $25 \mu \mathrm{g}$ of whole proteins was extracted from LCL, separated on a 7.5\% SDS-glycine gel electrophoresis and incubated with polyclonal antibodies directed against nibrin. After $1 \mathrm{~h}$ incubation with an anti-rabbit secondary antibody, enhanced chemoluminescence detection procedure was adopted to visualise antibody reaction.

\section{Immunoprecipitation analysis}

Lysates were prepared from three normal controls (1228, K2, 614), four NBS heterozygous $(34,1431,1451,708)$ and two NBS homozygous LCLs (668 and BS). Whole-cell extracts were prepared resuspending pellets in lysis buffer for $30 \mathrm{~min}$ (10 mM Tris- $\mathrm{HCl} \mathrm{pH} 7.5,150 \mathrm{mM} \mathrm{NaCl}, 1 \% \mathrm{NP}-$ 40, 0.5\% deoxycholic acid, $1 \mathrm{~mm}$ EDTA, $1 \mathrm{~mm}$ DTT, $1 \mathrm{~mm}$ PMSF). Proteins (3 mg) were purified with $40 \mu \mathrm{l}$ packed volume of protein A-agarose (Invitrogen Life Technologies, Scotland, UK), for $1 \mathrm{~h}$ at $4^{\circ} \mathrm{C}$ on a rotating wheel. After centrifugation at $10000 \mathrm{rpm}$ for $4 \mathrm{~min}$, purified samples were immunoprecipitated with $40 \mu \mathrm{l}$ packed volume of protein A-agarose and $5 \mu \mathrm{l}$ of Mre11 antiserum (Abcam, Cambridge, UK), for at least $2 \mathrm{~h}$ at $4^{\circ} \mathrm{C}$ on a rotating wheel. Samples were then centrifuged at $10000 \mathrm{rpm}$ for $4 \mathrm{~min}$ and the pellets were washed several times with lysis buffer.
Finally, the A-agarose beads were resuspended in loading buffer (125 mM Tris-HCl pH 6.8, 20\% glycerol, 10\% SDS, $100 \mathrm{~mm}$ DTT, $0.05 \%$ bromophenol blue), boiled for $3 \mathrm{~min}$ at $95^{\circ} \mathrm{C}$ and electrophoresed in a $8 \%$ SDS-polyacrylamide gel. After transfer to polyvinylidene difluoride membrane (Immobilon; Millipore, Bedford, MA, USA), filters were blocked for $1 \mathrm{~h}$ in 3\% skimmed milk in phosphate buffer at pH 7.4 and incubated overnight with monoclonal NBS1 antibody (dilution 1:5000) (Abcam). The filters were then incubated for $1 \mathrm{~h}$ with rabbit horseradish peroxidase secondary antibody (dilution 1:2000) (Amersham, Bucks, UK). The antibody reaction was checked by the enhanced chemoluminescence detection procedure according to the manufacturer's instructions (Amersham).

\section{Results}

In all the 13 NBS heterozygotes analysed, we found spontaneous chromosome instability consisting in chromosome and chromatid breakages and rearrangements (Table 1). The age of the subjects ranged from 6 to 77 years. Literature and personal data suggest an increase in spontaneous chromosome abnormalities frequency in healthy controls with age. ${ }^{27,28}$ Therefore, for the statistical analysis we consider two groups of control subjects. In the first group (age 5-49), the frequency of cells with aberrations varies between 0 and $9.1 \%$ with a mean value of $5.4 \%$ and a standard deviation (SD) of 2.9 , while in the second group (age 60-90), the frequency of cells with abnormalities ranges between 4 and $14 \%$ with a mean value of $9.2 \%$ and an SD of 3.5. The subject 708 (grandmother of 1548), who is the only person over 60 in the group of the 13 NBS heterozygotes, has a frequency of cells with aberrations of $21.6 \%$. This value is $+3 \mathrm{SD}$, when compared with the age-matched control group's mean value. The frequency of cells with aberrations in the remaining 12 NBS heterozygotes varies between 5 and $30 \%$ with a mean value of $10.7 \%$ and an SD of 7.9 . To test the difference of means in this sample and in the first group of controls we performed a Student-Fisher $t$-test assuming equal variance which is significant at $P=0.05$. We repeated the $t$-test by scoring only the chromosome rearrangements and we did not find a significantly increased frequency of these abnormalities in the NBS heterozygotes (mean $=2.5$; $\mathrm{SD}=1.9$ ) versus normal controls $($ mean $=2 ; \mathrm{SD}=1.4)$. The mean values of abnormal cells within each family are: $10.4 \%(\mathrm{SD}=5.5)$ in family 1 , $15.7 \%(\mathrm{SD}=10.9)$ in family 2 and $9.5 \%$ in family 3 . We tested difference of means between families 1 and 2 , which was, as expected, not significant. On the contrary, the $t$-test performed comparing only family 2 data with normal controls is highly significant $(P=0.01)$.

In Figure 1, we report the frequency of chromatid-type aberrations as evaluated in LCLs treated with 15 and 30 cGy 


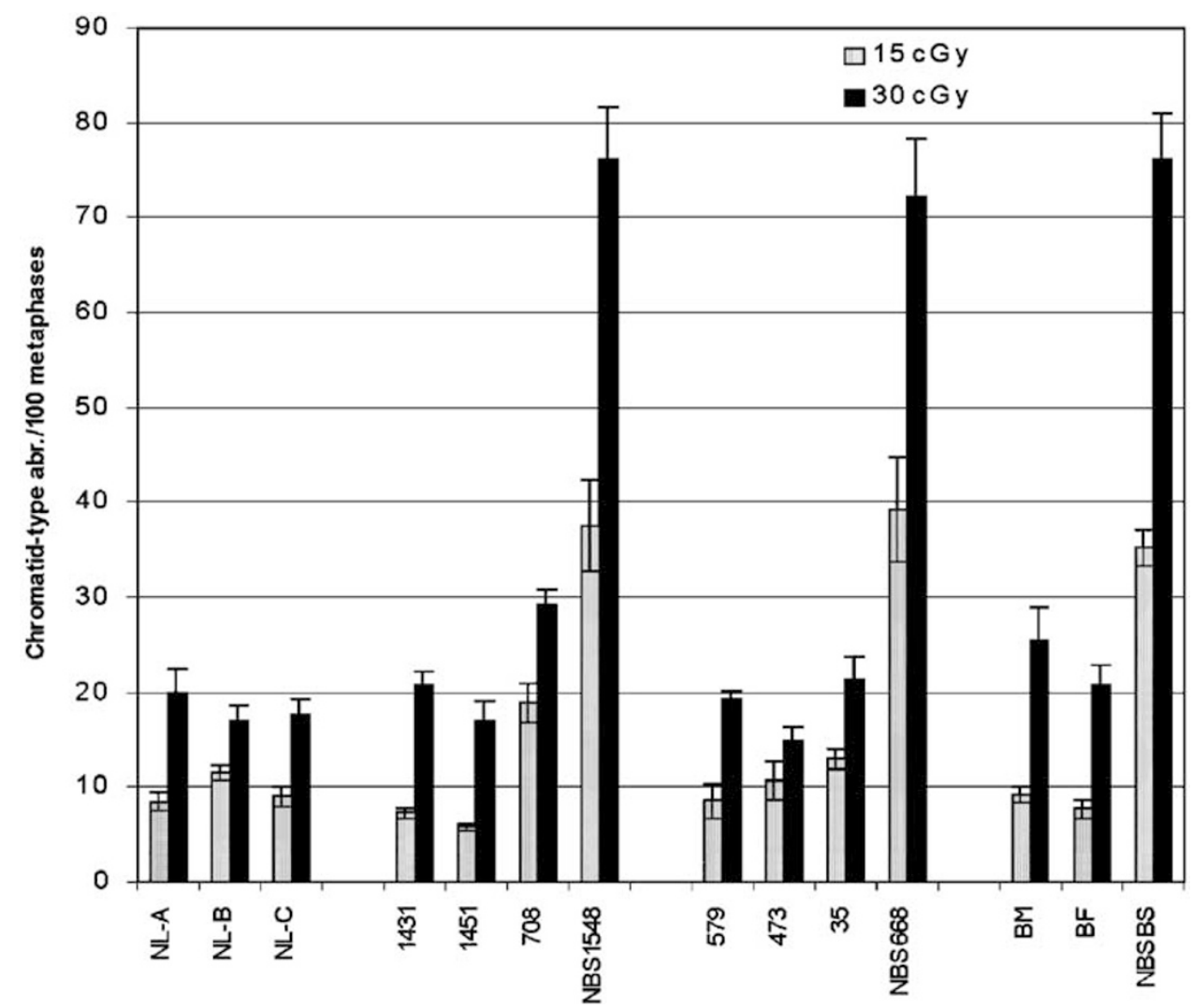

Figure 1 Frequency of chromosome aberrations induced by X-rays in G2-phase-treated LCLs from normal individuals (NL-A, NL$B, N L-C)$, NBS patients $(1548,668, B S)$ and NBS heterozygotes from family $1(1431,1451,708)$, family $2(579,473,35)$ and from family 3 (BM, BF). The yield of aberrations in the heterozygotes appears similar to that found in normal subjects. The only exception is represented by 708, who, at 15 cGy, shows a slightly increased radiosensitivity.

X-rays. NBS cells were about four-fold more radiosensitive than LCLs established from normal individuals. The yield of aberrations observed in cells established from the heterozygotes, on the contrary, appears similar to that found in LCLs of control subjects, with the only exception of the LCL 708, which shows an increased frequency of aberrations.

Western blot analysis results seem to indicate a slight reduction in the amount of nibrin in four out of seven heterozygotes analysed $(1431,1451,708,35)$ compared to three unaffected individuals (Figure 2). The densitometric analysis of film for the normal cells (four points) produced a mean value of $2.19 \pm 0.3$, while in heterozygotes a mean of $1.94 \pm 0.3$ was calculated (seven points). The ratio between these values corresponds to $88.5 \%$, ranging from the lowest value, $76 \%$ (LCLs 35 vs unaffected), to the highest $110 \%$ (LCLs 579 vs unaffected).

The immunoprecipitation assay confirms previous results $^{7}$ indicating that NBS cells, characterised by the presence of the classical mutation 657del5 in NBS1 gene, show an alternative form of nibrin with a lower molecular weight, termed $\mathrm{NBSp}^{70}$. In addition, we found that NBS

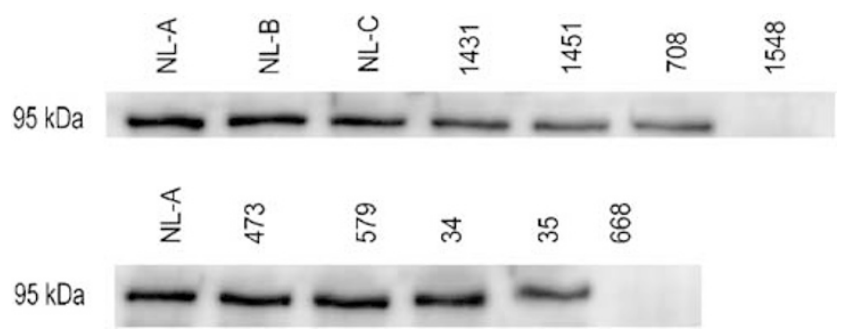

Figure 2 Immunoblot analysis carried out with polyclonal antisera for nibrin on whole-cell extracts from normal individuals (NL-A, NL-B, NL-C), NBS patients $(1548,668$ ) and NBS heterozygotes $(1431,1451,708,473,579,34,35)$. Nibrin protein was absent in the two NBS patients, while a slight reduction in the amount of protein was observed in 1431, 1451, 708 and 35.

cells, established from the patient 668 with the mutation 900del25, show an alternative form of nibrin with a molecular weight of approximately $55 \mathrm{kDa}$. The presence of such protein, together with the normal p95 protein, was also identified in LCL 34 established from a carrier of the 

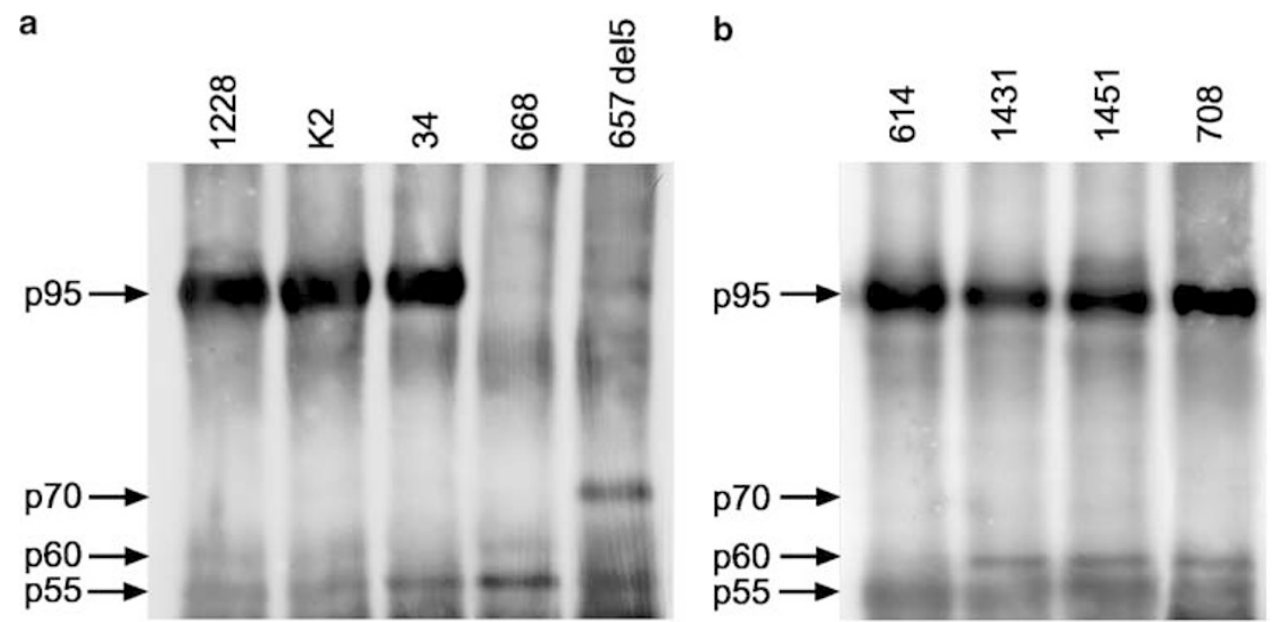

Figure 3 Immunoprecipitation analysis with monoclonal NBS1 antibody. (a) A 95-kDa protein in two wild-type LCLs (1228, K2), the NBSp ${ }^{70}$ in the NBS patient BS with the classic mutation (657del5) and an alternative form of nibrin with a molecular weight of approximately $55 \mathrm{kDa}$ in the NBS patient 668 (mutation 900del25). The presence of such protein, together with the normal p95 protein, is detected also in her heterozygous brother (34). (b) A 95-kDa protein in a wild-type LCL (614), and an alternative form of nibrin with a molecular weight of $60 \mathrm{kDa}$, together with the normal p95 protein, in three carriers $(1431,1451$ and 708$)$ from family 1 (mutation 835del4).

same family (Figure 3a). Signals of nibrin with a molecular weight lower than $70 \mathrm{kDa}$ but higher than that observed in LCLs NBS 668 and 34 were detected in the carriers 1431, 1451 and 708 from family 1 with mutation 835 del 4 (Figure 3b).

\section{Discussion}

In this report, we show that peripheral blood lymphocytes of NBS heterozygotes have a frequency of spontaneous chromosome aberrations significantly higher than that observed in normal subjects. The frequency of cells with abnormalities varies in the carriers, ranging from 5\% in the father of BS (family 3) to 30\% in the mother of 668 (family 2). The number of cells with abnormalities is particularly high also in 708 (grandmother, family 1), who is the oldest NBS heterozygote studied. An increase in chromosome aberrations with age has been reported in ataxia-telangiectasia (AT). ${ }^{29}$ There are no similar studies about NBS in the literature, but a clear reduction in the levels of radiation-induced apoptosis has been observed both in AT and NBS cells. It has been demonstrated that in normal subjects, the level of induced apoptosis depends on the age of the donors ${ }^{30}$ and that the frequency of chromosome alterations in peripheral blood lymphocytes increases with age. ${ }^{27,28}$ A decrement with the age in the ability of programmed death for cells with chromosome abnormalities could explain both the high frequency of chromosome rearrangements present in healthy donors over 60 and the higher risk to develop a cancer with increasing age. Chromosome instability in NBS patients' parents and relatives has been rarely investigated: some authors report no chromosome abnormalities, ${ }^{31-33}$ while others describe the presence of chromosome rearrangements. ${ }^{34,35}$ With the application of fluorescence in situ hybridisation (FISH) using whole-chromosome paints (WCPs), Stumm et al $^{14}$ showed that untreated LCLs from NBS and AT carriers displayed increased mean translocation frequencies compared to normal healthy controls, but this difference was not significant. In all NBS carriers we tested, apart from 34 (brother, family 2), we found sporadic rearrangements, involving different chromosomes at random, however, the $t$-test performed comparing only frequencies of chromosome rearrangements in NBS heterozygotes and normal controls was not significant. Presence of spontaneous cytogenetic damage in NBS carriers may be related to their inability to cope with physiologicallyinduced DNA damage. In the last few years, special attention has been addressed to endogenous reactiveactivated oxidative species (ROS) produced as a result of the mitochondrial activity. It is known that more than $80 \%$ of the energy released by low-energy transfer radiation in the living matter interacts with the DNA molecule through an indirect effect, which is mediated by the radicals produced by the $\mathrm{H}_{2} \mathrm{O}$ radiolysis. Accordingly, an increased rate of chromatid-type aberrations would have been expected in irradiated NBS heterozygote's LCLs in comparison with the values obtained in normal cell lines. Our data show increased frequency of chromosome damage only in the LCL 708, established from the oldest NBS carrier. Cells that die from excessive sensitivity to small single doses of ionising radiation but that are more resistant (per unit dose) to larger single doses have recently been reported. ${ }^{36}$ 
The authors hypothesise that mammalian cells can increase repair activity in response to excessive radiationinduced damage. Therefore, NBS carriers may trigger DNA repair processes after having reached a damage-sensing threshold. On the other hand, dose-dependent sensitivity towards induced damage is observed in NBS homozygous subjects who are defective in induced DNA strand breaks repair. It has recently been reported that NBS carriers can be differentiated from unaffected controls on the basis of increased frequency of stable-type chromosome changes in cells harvested $48 \mathrm{~h}$ after irradiation. ${ }^{15}$ It appears that the effect of Go/G1 treatment may differ from a G2-phase exposure. It is difficult, however, to accept this hypothesis, as cells from NBS patients are far more sensitive per unit of radiation when treated in G2 than in Go/G1 phase of cell cycle. $^{37}$

To our knowledge, no data are available in the literature on the amount of nibrin in NBS heterozygotes. Our densitometric analysis after immunoblotting indicates only a slight reduction in some of the LCLs from NBS carriers (Figure 2), and, at the present time, the significance of these results cannot be clarified.

Our study was carried out in three unrelated NBS families, two from northern Italy and one from Morocco. The mutation 835del4 detected in the NBS1 gene in family 1 is private, while the mutation 900del25 of the family 2 from Morocco has been recently found also in a Turkish NBS patient (personal communication). Both the mutations lead to a truncating protein as observed for the classical $657 \mathrm{del} 5,{ }^{5,24}$ which encodes a variant NBS1 protein of $70 \mathrm{kDa}$. The same alternative mode of translation has been hypothesised for the rare allele 835 del 4 of our Italian patient, which synthesises a peptide of approximately $60 \mathrm{kDa} .^{7}$ We detected this nibrin protein variant in three heterozygotes $(1431,1451,708)$ of family 1 (Figure 3b). By means of this assay, we were also able to identify the presence of an alternative form of nibrin with a molecular weight of approximately $55 \mathrm{kDa}$ in the NBS patient 668 with the mutation 900del25 and in her heterozygous brother (34) (Figure 3a). The immunoprecipitation assay appears, therefore, to be a reliable tool to detect NBS carriers on the basis of the production of nibrin protein variants with a molecular weight lower than $95 \mathrm{kDa}$. According to Maser et $a l^{7}$ the newly formed protein fragments retain the MRE11 interaction domain, partially restoring its localisation to the nucleus and possibly allowing, in this way, the viability of NBS patients. These observations are supported by experimental data showing that NBS1 mutant proteins truncated downstream of the FHA/BRCT domain, but retaining the MRE11-binding domain on the $\mathrm{C}$ terminus, restore the nuclear localisation of the MRE11/RAD50/NBS1 complex in NBS cell lines. ${ }^{38}$

No specific genotype-phenotype correlation has been identified in NBS till now: patients with different genotypes may express the same clinical phenotype ${ }^{8}$ and patients with the same genotype may have different phenotypes, mainly in respect of the risk of developing a lymphoma. ${ }^{11}$ It is, however, possible that different nibrin protein variants are correlated with differences in the cellular phenotype, that is, in the level of chromosome instability. If this holds true also for heterozygotes, this hypothesis could explain the high frequency of chromosome aberrations in subjects 473 and 579 from family 2 .

According to Seemanova, ${ }^{16}$ NBS heterozygous subjects have an increased risk of developing malignant tumours, and Varon et $a^{18}$ reported high frequency of mutation in NBS1 gene in children with acute lymphoblastic leukaemia. The NBS1 gene, however, seems not to be involved in the pathogenesis of the breast cancer, ${ }^{17}$ of the primary central nervous system lymphomas ${ }^{19}$ and of the B- and Tcell lymphomas. ${ }^{20-22}$ None of the 13 ascertained carriers in our families has at the moment developed a cancer, and a retrospective analysis of family 1 showed, among 172 subjects in four generations, only one case of pancreatic carcinoma and two cases of lung cancer having arisen on silicosis in the maternal family and two cases of breast cancer in the paternal family. Up to now, data collected from epidemiological studies of NBS heterozygotes and mutation analysis of NBS1 gene in cancer patients have not been able to exclude or confirm the existence of an overall increased cancer risk for NBS carriers. The role of the NBS1 gene in the pathogenesis of cancer is still unclear, but it seems possible that heterozygous mutations in the NBS1 gene can confer an increased risk of developing specific types of malignant tumours. Further studies may help to clarify this point.

\section{Acknowledgements}

The technical assistance of Annamaria Lanfranchi, Mario Battini and Maria Rosaria Abate is acknowledged. We thank A. Merante for image processing.

\section{References}

1 Matsuura S, Weemaes C, Smeets D et al: Genetic mapping using microcell-mediated chromosome transfer suggests a locus for Nijmegen breakage syndrome at chromosome 8q21-24. Am J Hum Genet 1997; 60: 1487-1494.

2 Saar K, Chrzanowska KH, Stumm M et al: The gene for the ataxiatelangiectasia variant, Nijmegen breakage syndrome, maps to a 1-cM interval on chromosome 8q21. Am J Hum Genet 1997; 60: 605-610.

3 Cerosaletti KM, Lange E, Stringham HM et al: Fine localization of the Nijmegen breakage syndrome gene to 8q21: evidence for a common founder haplotype. Am J Hum Genet 1998; 63: 125-134.

4 Matsuura S, Tauchi H, Nakamura A et al: Positional cloning of the gene for Nijmegen breakage syndrome. Nat Genet 1998; 19: 179-181.

5 Varon R, Vissinga C, Platzer M et al: Nibrin, a novel DNA doublestrand break repair protein, is mutated in Nijmegen breakage syndrome. Cell 1998; 93: 467-476.

6 Carney JP, Maser RS, Olivares H et al: The hMre11/hRad50 protein complex and Nijmegen breakage syndrome: linkage of doublestrand break repair to the cellular DNA damage response. Cell 1998; 93: 477-486. 
7 Maser RS, Zinkel R, Petrini JH: An alternative mode of translation permits production of a variant NBS1 protein from the common Nijmegen breakage syndrome allele. Nat Genet 2001; 27: 417-421. [Letter].

8 Hiel JA et al: (The International Nijmegen Breakage Syndrome Study Group). Nijmegen breakage syndrome. Arch Dis Child 2000; 82: 400-406.

9 van der Burgt I, Chrazanowska KH, Smeets D, Weemaes C: Nijmegen breakage syndrome. J Med Genet 1996; 33: 153-156.

10 Concannon PJ, Gatti RA. Nijmegen Breakage Syndrome. in: GeneReviews at GeneTests-GeneClinics: Medical Genetics Information Resource [database online]. Copyright, Seattle; University of Washington. 1997-2003, 1999 Available at http://www. geneclinics.org.

11 Maraschio P, Danesino C, Varon R, Tiepolo L: Corpus callosum hypoplasia and associated brain anomalies in Nijmegen breakage syndrome. J Med Genet 2002; 39: E25.

12 Resnick IB, Kondratenko I, Togoev O et al: Nijmegen breakage syndrome: clinical characteristics and mutation analysis in eight unrelated Russian families. J Pediatr 2002; 140: 355-361.

13 Maraschio P, Antoccia A, Pecile V, Tanzarella C, Tiepolo L: Increased frequency of chromosome aberrations in Nijmegen Breakage Syndrome heterozygotes. Ann Genet 2001; 44: 562 (Suppl). [Abstract].

14 Stumm M, Neubauer S, Keindorff S, Wegner RD, Wieacker P, Sauer $\mathrm{R}$ : High frequency of spontaneous translocations revealed by FISH in cells from patients with the cancer-prone syndromes ataxia telangiectasia and Nijmegen breakage syndrome. Cytogenet Cell Genet 2001; 92: 186-191.

15 Neubauer S, Arutyunyan R, Stumm M et al: Radiosensitivity of ataxia telangiectasia and Nijmegen breakage syndrome homozygotes and heterozygotes as determined by three-color FISH chromosome painting. Radiat Res 2002; 157: 312-321.

16 Seemanova E: An increased risk for malignant neoplasms in heterozygotes for a syndrome of microcephaly, normal intelligence, growth retardation, remarkable facies, immunodeficiency and chromosomal instability. Mutat Res 1990; 238: $321-324$

17 Carlomagno F, Chang-Claude J, Dunning AM, Ponder BA: Determination of the frequency of the common 657Del5 Nijmegen breakage syndrome mutation in the German population: no association with risk of breast cancer. Genes Chromosomes Cancer 1999; 25: 393-395.

18 Varon R, Reis A, Henze G, von Einsiedel HG, Sperling K, Seeger K: Mutations in the Nijmegen Breakage Syndrome gene (NBS1) in childhood acute lymphoblastic leukemia (ALL). Cancer Res 2001; 61: 3570-3572.

19 Hama S, Matsuura S, Tauchi H et al: Absence of mutations in the NBS1 gene in B-cell malignant lymphoma patients. Anticancer Res 2000; 20: 1897-1900.

20 Rischewski J, Bismarck P, Kabisch H, Janka-Schaub G, Obser T, Schneppenheim R: The common deletion 657del5 in the Nibrin gene is not a major risk factor for $\mathrm{B}$ or $\mathrm{T}$ cell non-Hodgkin lymphoma in a pediatric population. Leukemia 2000; 14: $1528-1529$.

21 Stanulla M, Stumm M, Dieckvoss BO et al: No evidence for a major role of heterozygous deletion 657del5 within the NBS1 gene in the pathogenesis of non-Hodgkin's lymphoma of childhood and adolescence. Br J Haematol 2000; 109: 117-120.
22 Stumm M, von Ruskowsky A, Siebert R et al: No evidence for deletions of the NBS1 gene in lymphomas. Cancer Genet Cytogenet 2001; 126: 60-62.

23 Tupler R, Marseglia GL, Stefanini $M$ et al: A variant of the Nijmegen breakage syndrome with unusual cytogenetic features and intermediate cellular radiosensitivity. J Med Genet 1997; 34: 196-202.

24 Maraschio P, Danesino C, Antoccia A et al: A novel mutation and novel features in Nijmegen breakage syndrome. J Med Genet 2001; 38: 113-117. [Letter].

25 Barth E, Demori E, Pecile V, Zanazzo GA, Malorgio C, Tamaro P: Anthracyclines in Nijmegen breakage syndrome. Med Pediatr Oncol 2003; 40: 122-124.

26 Antoccia A, Stumm M, Saar $\mathrm{K}$, Ricordy $\mathrm{R}$, Maraschio $\mathrm{P}$ Tanzarella C: Impaired p53 mediated DNA damage response, cell cycle disturbances and chromosome aberrations in Nijmegen Breakage Syndrome lymphoblastoid cell lines. Int J Radiat Biol 1999; 75: 583-591.

27 Hedner K, Hogstedt B, Kolnig AM, Mark-Vendel E, Strombeck B, Mitelman F: Sister chromatid exchanges and structural chromosome aberrations in relation to age and sex. Hum Genet 1982; 62: 305-309.

28 Bolognesi C, Abbondandolo A, Barale R et al: Age-related increase of baseline frequencies of sister chromatid exchanges, chromosome aberrations, and micronuclei in human lymphocytes. Cancer Epidemiol Biomarkers Prev 1997; 6: 249-256.

29 Al Saadi A, Palutke M, Kumar GK: Evolution of chromosomal abnormalities in sequential cytogenetic studies of ataxia telangiectasia. Hum Genet 1980; 55: 23-29.

30 Crompton NE, Shi YQ, Emery GC et al: Sources of variation in patient response to radiation treatment. Int J Radiat Oncol Biol Phys 2001; 49: 547-554.

31 Conley ME, Spinner NB, Emanuel BS, Nowell PC, Nichols WW: A chromosomal breakage syndrome with profound immunodeficiency. Blood 1986; 67: 1251-1256.

32 Wegner RD, Metzger M, Hanefeld $\mathrm{F}$ et al: A new chromosomal instability disorder confirmed by complementation studies. Clin Genet 1988; 33: 20-32.

33 Green AJ, Yates JR, Taylor AM et al: Severe microcephaly with normal intellectual development: the Nijmegen breakage syndrome. Arch Dis Child 1995; 73: 431-434.

34 Weemaes CM, Hustinx TW, Scheres JM, van Munster PJ, Bakkeren JA, Taalman RD: A new chromosomal instability disorder: the Nijmegen breakage syndrome. Acta Paediatr Scand 1981; 70: $557-564$.

35 Maraschio P, Peretti D, Lambiase $\mathrm{S}$ et al: A new chromosome instability disorder. Clin Genet 1986; 30: 353-365.

36 Marples B, Lambin P, Skov KA, Joiner MC: Low dose hyperradiosensitivity and increased radioresistance in mammalian cells. Int I Radiat Biol 1997; 71: 721-735.

37 Taalman RDFM, Jaspers NG, Scheres JMJC, de Wit J, Hustinx TWJ: Hypersensitivity to ionizing radiation, in vitro, in a new chromosomal breakage disorder, the Nijmegen Breakage Syndrome. Mutat Res 1983; 112: 23-32.

38 Tauchi H, Kobayashi J, Morishima $\mathrm{K}$ et al: The forkheadassociated domain of NBS1 is essential for nuclear foci formation after irradiation but not essential for hRAD50 - hMRE11 - NBS1 complex DNA repair activity. $J$ Biol Chem 2001; 276: 12-15. 